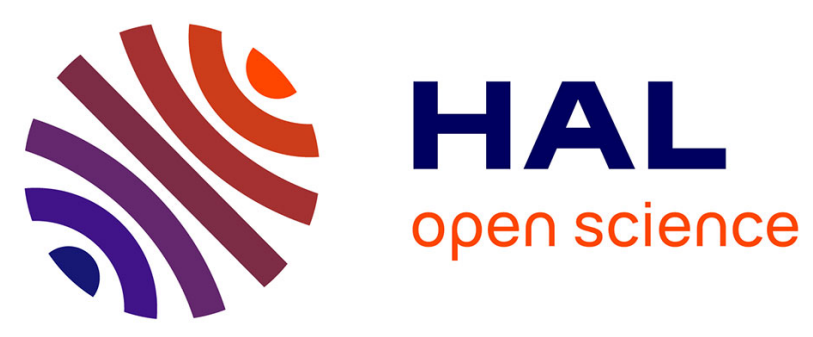

\title{
Management of established pressure ulcer infections in spinal cord injury patients
}

\author{
A. Dinh, F. Bouchand, B. Davido, C. Duran, P. Denys, A. Lortat-Jacob, M. \\ Rottman, J. Salomon, L. Bernard
}

\section{- To cite this version:}

A. Dinh, F. Bouchand, B. Davido, C. Duran, P. Denys, et al.. Management of established pressure ulcer infections in spinal cord injury patients. Médecine et Maladies Infectieuses, 2019, 49 (1), pp.9 16. $10.1016 / \mathrm{j}$.medmal.2018.05.004 . hal-03485636

\section{HAL Id: hal-03485636 https://hal.science/hal-03485636}

Submitted on 20 Dec 2021

HAL is a multi-disciplinary open access archive for the deposit and dissemination of scientific research documents, whether they are published or not. The documents may come from teaching and research institutions in France or abroad, or from public or private research centers.
L'archive ouverte pluridisciplinaire HAL, est destinée au dépôt et à la diffusion de documents scientifiques de niveau recherche, publiés ou non, émanant des établissements d'enseignement et de recherche français ou étrangers, des laboratoires publics ou privés.

\section{(ㄷ)(1) $\$$}

Distributed under a Creative Commons Attribution - NonCommerciall 4.0 International 


\title{
Prise en charge des infections sur escarre chez le patient blessé médullaire
}

\section{Management of established pressure ulcer infections in spinal cord injury patients}

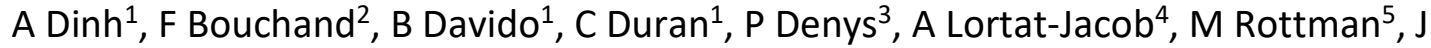 \\ Salomon ${ }^{1,6}$, L Bernard $^{1,7}$
}

\author{
${ }^{1}$ Service des Maladies infectieuses et tropicales, Hôpital R. Poincaré, Hôpitaux universitaires \\ Paris lle de France Ouest, AP-HP, UVSQ, Garches, France \\ 2 Pharmacie, Hôpital R. Poincaré, Hôpitaux universitaires Paris lle de France Ouest, AP-HP, \\ UVSQ, Garches, France
}

${ }^{3}$ Service de Neuro-urologie, Hôpital R. Poincaré, Hôpitaux universitaires Paris lle de France Ouest, AP-HP, UVSQ, Garches, France

${ }^{4}$ Service de Chirurgie Orthopédique, Hôpital R. Poincaré, Hôpitaux universitaires Paris lle de France Ouest, AP-HP, UVSQ, Garches, France

${ }^{5}$ Laboratoire de Microbiologie, Hôpital R. Poincaré, Hôpitaux universitaires Paris lle de France Ouest, AP-HP, UVSQ, Garches, France

${ }^{6}$ UMR 1181, Inserm, Institut Pasteur, Paris, France

${ }^{7}$ Département des Maladies infectieuses et tropicales, Hôpital Bretonneau, Université F. Rabelais, Tours, France

\section{Corresponding author}

Aurélien Dinh

Service des Maladies infectieuses et tropicales,

Hôpital R. Poincaré, 
HU-PIFO, AP-HP, UVSQ

104 Bd R. Poincaré,

92380 Garches

Phone number: + 33147104432

Email address: aurelien.dinh@aphp.fr 


\section{Résumé}

Objectifs. - Les escarres sont fréquentes chez les patients blessés médullaires. Elles sont associées à une importante morbi-mortalité et constituent un fardeau médico-économique majeur. Malgré leur fréquence, la physiopathologie et la gestion optimale ne sont toujours pas connues. La plupart des données disponibles proviennent d'études non comparatives, notamment en ce qui concerne l'utilisation d'antimicrobiens.

Méthodes. - Nous présentons un examen critique de la littérature et nous focalisons surtout sur les traitements antimicrobiens dans cette situation.

Résultats. - Le diagnostic d'infection repose essentiellement sur l'examen clinique car les prélèvements microbiologiques ne sont dans ce cas pas utiles. En outre, une identification microbiologique fiable est un défi majeur mais devrait aider à sélectionner un traitement antimicrobien adapté. Les examens d'imagerie peuvent être utiles mais ne peuvent remplacer l'examen clinique. Le choix de l'antibiothérapie doit tenir compte des dommages collatéraux écologiques éventuels dans une population vulnérable. Ainsi, la durée de l'antibiothérapie doit être aussi courte que possible, adaptée à l'identification microbiologique, et avec une biodisponibilité appropriée.

Conclusion. - La prise en charge des escarres infectées est une préoccupation majeure pour les personnes handicapées qui sont déjà très exposées aux traitements antibiotiques et à la colonisation des organismes multi-résistants. Plus de données sont nécessaires.

Mots clés : escarre ; blessé médullaire ; bactérie multi-résistante 


\section{Abstract}

Objectives. - Pressure ulcers are frequently observed in spinal cord injury (SCl) patients. They can be life-threatening and are a major medico-economic burden. Despite their frequency, their pathophysiology and optimal management are still poorly understood. Most available data comes from non-comparative studies, especially in terms of antimicrobial use.

Methods. - We performed a critical review of the literature and opinions of infectious disease specialists based in a French expert center for this disease. We mainly focused on antimicrobial treatments prescribed in this situation.

Results. - These infections are usually clinically diagnosed. Microbiological samples are not the gold standard for this assessment. Furthermore, reliable microbiological identification is a major challenge but should help select antimicrobial treatment. Imaging technique could be helpful but cannot replace the physical examination. The choice of antimicrobials must consider the potential ecological collateral damages in this vulnerable population. Antimicrobial therapy should be as short as possible, adapted to the microbiological identification, and must have suitable bioavailability.

Conclusion. - Management of infected pressure ulcers is a major concern in disabled patients already highly exposed to antimicrobial treatment and multidrug-resistant organisms colonization. Extensive data is required.

Keywords: pressure ulcers, spinal cord injury, multidrug-resistant bacteria 


\section{Introduction}

Pressure ulcers in spinal cord injury $(\mathrm{SCl})$ patients are a potential lifelong complication that can interfere with the patient's physical, psychological, and social well-being and impact the overall quality of life [1].

Although pressure ulcers in elderly patients are mostly due to arteriopathy, malnutrition, or immunosuppression, $\mathrm{SCl}$ patients are subject to pressure ulcers because of numerous risk factors: neurological disorders reducing mobilization, potential undernutrition, confinement to bed, and vascular disorders promoting the lesions. Also, as the median age of SCI patients is younger, invasive exploration and invasive treatments are favored.

Pressure ulcers are frequent, and their clinical spectrum is wide. They readily become superinfected and can lead to sepsis. Their occurrence is potentially associated with several hospitalizations and a longer length of stay [1-4]. Furthermore, pressure ulcers are an important economic burden to the healthcare system. Therefore, prevention is a major goal during management and requires identification and avoidance of risk factors.

However, few epidemiological, pathophysiological, or clinical studies on pressure ulcers are available. The management of these patients relies on low evidence-based data, especially in terms of antimicrobial treatment. There is no clinical trial or comparative study on antimicrobial treatment duration, class of antimicrobial therapy, or route of administration (oral versus parenteral). The optimal management is unknown and is mainly based on experts' opinions.

Thus, the choice of antimicrobial therapy is crucial in case of clinical sepsis. However, it should be made with caution in this population of patients as they are already highly exposed to antimicrobial treatments and have a high rate of multidrug-resistant organisms (MDRO) infections [5,6]. 
We present available data on this pathology with an infectious disease specialists' point of view.

\section{Established pressure ulcers: definition and overview}

\subsection{Definition and classification}

In 1989, the National Pressure Ulcer Advisory Panel defined a pressure ulcer as a skin lesion of ischemic origin related to compression of soft tissues between a hard surface and bony preeminence [7]. The pressure ulcer is thus a variable deep tissue loss, occurring at pressure point levels.

They are classified into four stages (Table I) $[7,8]$.

\subsection{Epidemiology}

The prevalence of pressure ulcers in $\mathrm{SCl}$ patients ranges from $10.2 \%$ to $30 \%$ [2,9-12]. An increased prevalence has been reported in recent years, which could not be explained by patients' characteristics or years since injury $[2,7,11]$.

For these patients, the risk of pressure ulcers is steady during the first 10 years and increases 15 years post injury, depending on age [11].

In a retrospective study of prevalence, duration, and severity of pressure ulcers among 553 veterans presenting with $\mathrm{SCl}, 215$ (39\%) patients had previously visited healthcare centers or received home care for pressure ulcers [13]. Duration of ulcers ranged from 1 week to 3 years. Stage IV pressure ulcers were the most prevalent (56\%). A high number and severity 
of ulcers could predict unfavorable outcome, which was defined as not healing during the year of follow-up.

Taghipoor et al. reported overall incidence rates of $28.2 \%$ in patients presenting with nontraumatic $\mathrm{SCl}$ and $71.8 \%$ in those presenting with $\mathrm{SCl}$ of traumatic etiology [14]. However, this study was biased as most participants had low income and had motor- and sensorycomplete injuries.

Overall, in community-dwelling SCl patients, stage III and IV pressure ulcers accounted for $25 \%$ of total ulcers observed, while the highest incidence was associated with stage II $[2,4,15]$. The most common pressure ulcer site was the sacrum [15].

\subsection{Risk factors}

Risk factors for pressure ulcer may be intrinsic (clinical) or extrinsic (mechanical) (Table II) [8]. The management of pressure ulcers needs to take all factors into account and attempt to correct them to facilitate recovery and prevent recurrences.

\subsection{Different types of pressure ulcers}

Pressure ulcers may be differentiated into two types:

- $\quad$ infected pressure ulcers with inflammatory local signs which may be associated with acute sepsis, cellulitis, endocarditis, or septic arthritis. Osteomyelitis has been reported in $17 \%$ to $32 \%$ of infected ulcers $[16,17]$. In this case, pressure ulcers are associated with a high case fatality [18]; 
- $\quad$ non-infected but colonized pressure ulcers, with a more torpid course, sometimes with mild and non-septic presentations.

Distinguishing these two presentations is difficult and requires the expertise of an experienced physician. The transition from colonization to infection is linked to complex factors related to host-bacterium interactions: the site, size and depth of the lesion, the host's general and immune condition, and the virulence of the bacterial species [19]. Rather than bacterial quantification, a rapid increase in bacterial growth plays a role in this phenomenon [20].

It is also necessary to differentiate pressure ulcers without bone involvement from those associated with osteitis. Their management differs, particularly in terms of antimicrobial treatment.

\section{Diagnosis of pressure ulcer infection}

Pressure ulcer infection is primarily an infection of the cutaneous and subcutaneous soft tissues. However, the infection may extend to the underlying bone and induce contiguous osteitis. Osteitis is often difficult to formally diagnose.

\subsection{Clinical diagnosis of pressure ulcer infection}

The physical examination must be meticulous and define the spread of the pressure ulcer to the deep tissues. An experienced physician should preferably conduct it. Major delay in diagnosis is frequently observed in $\mathrm{SCl}$ patients due to the sensory neurological deficit. 
Some apparently non-extensive lesions may reveal marked subcutaneous involvement. The size, extension, and gross appearance of the pressure ulcer must be reported to monitor its course on treatment. The local criteria for infection are not specific and consist in a local increase in temperature, erythema, pain, and discharge. None of these criteria have a good sensitivity or specificity. The systemic signs are fever and signs of sepsis.

The diagnosis of osteitis in a context of pressure ulcer is difficult and not easily diagnosed clinically. In a study of 36 patients presenting with suspected osteitis associated with pressure ulcers, the clinical examination accuracy was only $53 \%$, with a sensitivity of $33 \%$ and a specificity of $60 \%$ [21].

A suggestive clinical sign of osteitis is the absence of clinical improvement in spite of a correctly implemented treatment for pressure ulcer [22].

Investigation for bone contact could be carried out with sterile metal device to investigate for rough contact with bone tissue. The presence of bone contact in a context of pressure ulcer suggests osteitis; its absence has a high negative predictive value $[23,24]$.

\subsection{Imaging tests}

Imaging tests are not usually required for the management of pressure ulcers.

However, in case of extended lesions which are difficult to evaluate at bedside, a CT scan allows for better assessment of the area, especially with urological and digestive lesions. It should be performed if deep extension of the lesion is suspected, or before surgery. Moreover, when osteitis is suspected, the CT scan provides arguments for its diagnosis.

Magnetic resonance imaging (MRI) has become more common in the diagnosis and 
management of osteitis due to pressure ulcers in $\mathrm{SCl}$ patients. In a study in which $37 \mathrm{SCl}$ patients presenting with pressure ulcers underwent MRI, acute cortical bone erosion and abnormal bone marrow edema accurately predicted osteitis, with strong agreement between observers [25]. The MRI could therefore be useful in case of suspected osteitis without probe-to-bone test to plan for surgery.

Data on scintigraphy or PET scan is scarce in this indication and seems to be of little added value compared with the CT scan and MRI. Their only indication from our point of view is contraindication to the former imaging techniques.

Despite imaging studies, bone biopsy and histopathological evaluation remain the "gold standard" for the diagnosis of osteitis [26].

\subsection{Microbiology}

Superficial specimens are almost always positive and do not enable the diagnosis of infection. Even microbiological data obtained from deep tissue biopsy is insufficient as the sole criterion for the diagnosis of infection as they can be contaminated. As the diagnosis of infection is mostly clinical, deep samples can be useful for directing the antimicrobial therapy [26]. We recommend collecting at least three samples at the infected site.

Specimens are only to be obtained in the event of clinical diagnosis of infection, and before antimicrobial prescription.

In our center, specimens are acquired at bedside only in case of clinical failure of the firstline antimicrobial treatment, or in case of arthritis. During surgery, per-operative bone and joint infection sampling is always performed after cleaning. 
There are various sample types and the sampling modalities must be specified, although there is no consensus about a reference method. The wound is usually prepared by meticulous debridement and cleaned with normal saline or possibly with an antiseptic (which is then abundantly rinsed not to inhibit bacterial growth) before the specimens are obtained. The various techniques consist in: superficial swabbing, usually described as poorly effective, needle aspiration, soft tissue biopsy, and bone biopsy [27]. The latter must be implemented via healthy tissue to prevent contamination. No study has compared these techniques. However, it may be considered that the deeper the sampling is, the most informative it is. Deep tissue specimens are therefore to be preferred.

The aim is to identify the bacterium or bacteria responsible for the infection. The local commensal flora should not contaminate the sample. The bacteriological results will help select the most appropriate antimicrobial therapy with the narrower activity spectrum possible.

Lastly, it is important to be as little invasive as possible and to inflict the least damage.

It is difficult to precisely identify the microorganisms responsible for colonization. To limit the false positives, deep specimens by needle puncture or irrigation-aspiration or even by subcutaneous tissue and/or bone biopsy should be taken; this will also help quantify the results (semi quantitative count). We implemented a specific protocol at our center: samples are mechanically disrupted in sterile water with stainless steel beads using a Retsch MM400 157 beadmill (Verder ${ }^{\circledast}$, Cergy-Pontoise, France). Beadmilled sample suspensions are then cultured on both solid Columbia agar plates incubated under aerobic and anaerobic atmospheres, and blood culture aerobic and anaerobic vials incubated in a Bactec FX automate (BD Diagnostics ${ }^{\circledR}$, Sparks, MD). Vials are automatically monitored for 7 days for 
aerobic vials and 15 days for anaerobic vials. Positive isolates are identified by mass spectrometry using a Microflex LT instrument and the current CE-IVD marked Biotyper software (Bruker Daltonique ${ }^{\circledR}$, Wissenbourg, France).

Positive result for suction drainage fluid culture is a poor prognostic factor in septic orthopedic surgery and reflects the presence of numerous residual bacteria $[28,29]$. This has not been proven in infected pressure ulcer surgery, and the interpretation of positive bacteriological culture results is difficult. Contaminant organisms should be distinguished from infectious organisms, because the inoculum of the flora-colonizing pressure ulcers is frequently high and multimicrobial and often leads to suction drainage fluid contamination. If a new microorganism that was not present per-operatively is identified by suction drainage fluid culture, several teams recommend transcutaneous biopsy of the focus to determine whether the microorganism is present at the site of infection.

The gold standard for diagnosing osteitis is the association of bacteriologically positive bone specimens and histological study findings in favor of infection [26,30-33].

In a retrospective study performed in our center, 168 surgical samples were analyzed among 101 spinal cord-injured patients with infected pressure ulcers [27].

To improve the use of bacteriological results, tissue specimens were sampled the end of the surgical procedure from unbridled and cleaned ulcers. The most frequently isolated species were Enterobacteriaceae (29\%), followed by staphylococci $(28 \%)$ and enterococci (16\%). Escherichia coli and Proteus mirabilis were the dominant species among Enterobacteriaceae. Overall, $50 \%$ of samples were polymicrobial and $7 \%$ had a positive culture with anaerobes. Moreover, $17(10 \%)$ had a negative culture. 


\section{Treatment of infected pressure ulcers}

\subsection{Local care}

Treatments aim to control and cure the infection and to achieve rapid wound healing [26].

The local management of infected pressure ulcers requires major local care, sometimes in the operating room. Dressings must be regularly changed [8].

Several small-scale studies tried to compare products. In a randomized clinical trial with 83 subjects included, Hollisaz et al. observed that hydrocolloid dressings $(n=28)$ had a better healing power, regardless of ulcer localization and stage $(74 \% ; P<0.005)$, than topical phenytoin (40\%; $n=28)$ or simple dressings $(27 \% ; n=27)$ [34].

Using a phenytoin solution, Subbanna et al. observed non-significant improvements when compared with normal saline $(P=0.132)$ [35]. Kaya et al. assessed the effectiveness of an occlusive hydrogel type dressing compared with a povidone-iodine soaked gauge dressing. No statistically significant difference was observed [36].

In one study, platelet gel use was only found effective within the first two weeks of treatment considering wound volume reduction [37].

As the relative effects of antiseptic on pressure ulcers are not clear, there is no consensus concerning the best dressing method $[8,38]$. In our center, in the absence of convincing data, the wound is cleaned with normal saline.

\subsection{Surgery}


In the event of a life-threatening infection, a surgical procedure must be performed urgently. In other cases, it can be delayed depending on the course and extent of the pressure ulcer and the potential for fasciocutaneous coverage [8].

In that case, the pressure ulcer should be adequately debrided and covered with a flap containing muscle or fascia [39-41].

However, surgical complications and recurrences are frequent. In a retrospective study of 48 spinal cord-injured patients with pressure ulcers, surgical complications and recurrences occurred respectively in 19 patients (39.6\%) and 38 patients (79.2\%) [42]. There was a link between ulcer localization and postoperative wound separation, and the length of hospitalization, but not with patient's age, level of spinal cord injury, number and grade of ulcers, diabetes, and presence or absence of osteitis.

In a prospective study of 352 patients with 421 skin flaps, complications occurred in $21 \%$ of cases with mainly suture line dehiscence (31\%) and infection (25.2\%) [43].

However, when a scheduled pre- and postoperative protocol is applied, the recurrence rate is lower [44].

Some authors built a solid predictive model of closure outcome during flap reconstruction using creatinine, hematocrit, hemoglobin, and prealbumin levels [45].

\subsection{Negative-pressure wound therapy}

Negative-pressure wound therapy (NPWT) refers to any device that applies differential suction (i.e., reduced local pressure) to wounds. The most commonly used are vacuumassisted closure (VAC) therapy systems [46]. They are mostly indicated for patients presenting with chronic, acute, traumatic, subacute, and dehisced wounds; pressure ulcers; 
flaps and grafts. This therapy has shown very interesting results in the management of pressure ulcers to promote wound healing [47].

Its proven mechanisms of action are the increase in local blood flow, stimulation of angiogenesis and formation of granulation tissue, stimulation of cell proliferation, reduction of the size and complexity of the wound, and removal of soluble healing inhibitors from the wound [48].

There is no scientific evidence demonstrating the reduction of bacterial load by NPWT, and further exploration is required $[48,49]$. In an in vitro model of wound bacterial biofilm, a significant reduction in biofilm bacteria was obtained after two weeks of NPWT. When combined with silver impregnated foam, a more significant reduction was observed within 24 hours [50].

Batra et al. reported the case of a 32-year-old man presenting with a large sacral grade IV pressure ulcer, treated with NPWT. The wound was completely healed in six weeks [51].

On the basis of these case reports, several experts provided recommendations to identify which type of infected wounds would benefit from NPWT. However, in case of infected pressure ulcers, major complications can occur such as bleeding or sepsis. It is therefore recommended not to use this system in case of gross infection, signs of sepsis, recurrent deep wound infection, presence of a pseudoaneurysm, lack of local wound hemostasis, unprotected vascular anastomoses, or foam placement directly over weakened or irradiated vessels [52].

Furthermore, for $\mathrm{SCl}$ patients, autonomic hyperreflexia can occur during NPWT. NPWT should in that case be discontinued.

\subsection{Hyperbaric oxygen therapy}


As data on the efficacy of hyperbaric oxygen therapy is scarce [38], such technique should not be used to treat infected pressure ulcers in $\mathrm{SCl}$ patients.

\subsection{Systemic antimicrobial therapy for pressure ulcers}

In the absence of infection, the benefit of prescribing antimicrobials or local antiseptics has not been proven. Bacterial colonization is constant and should not be treated in the absence of demonstrated benefit and given the risk of selecting MDRO [53]. Some authors have suggested that the presence of colonizing flora promotes the positive course of the wounds. The flora should therefore be spared [54].

\subsubsection{Infected pressure ulcer without osteitis}

The National Institute for Clinical Excellence (NICE) has defined the presence of local or systemic clinical signs of sepsis as an indication for systemic antimicrobial therapy [53].

Pressure ulcers without associated osteitis must be managed in the same way as dermohypodermitis, i.e. empirical antimicrobial therapy and local care. Treatment duration of infectious cellulitis is 7 to 15 days $[55,56]$. Indication for empirical antimicrobial therapy relates to the risk of cellulitis, osteitis, and destructive lesions of the neighboring organs. The infection may give rise to septicemia with remote spread, severe sepsis, and even septic shock [8].

In most cases, the antimicrobial therapy is empirical and must take into account a potential infection with multiple microorganisms and the frequent presence of Enterobacteriaceae and anaerobes in the event of a perineal site. 
In our center, we suggest the use of intravenous amoxicillin $2 \mathrm{~g}$ three times a day and clavulanic acid $125 \mathrm{mg}$ three times a day for 7 days in the absence of septic shock. The personal and local epidemiology should however be considered, especially in severe sepsis where broad-spectrum antimicrobials such as ureidopenicillins or carbapenems are the recommended antimicrobial agents. If deep specimens have been obtained, treatment can be adapted subsequently.

\subsubsection{Infected pressure ulcer with osteitis}

In most cases, pressure ulcers with osteitis require surgery with excision of the infected tissues and lavage, followed by coverage of the tissue loss and antimicrobial therapy. The latter aims to target the microorganisms identified per-operatively and must be administered at the same dosage as treatment for bone and joint infections.

As in all cases of orthopedic surgery in a context of infection, antimicrobial therapy prior to the procedure should be prohibited, except in case of life-threatening situation, not to interfere with the deep bacteriological specimens to be obtained during the procedure. Antimicrobials should not be administered during the 15 days preceding surgery. On the basis of in vitro data, this time interval prevents the sampling of antimicrobial-impregnated bone tissue [57].

Once the surgical procedure has been completed, the antimicrobial therapy must be immediately initiated. Its objective is to reinforce the effects of the surgical treatment by attempting to eradicate any residual bacteria. High-dose combination treatment by parenteral route is the most frequently used to induce high plasma concentrations and 
obtain correct bone concentrations. In our center the empirical postoperative antimicrobial treatment is amoxicillin high dose ( $2 \mathrm{~g}$ three times a day) associated with clavulanic acid (0.125 mg three times a day).

Subsequently, on the basis of the antimicrobial susceptibility test results of per-operative specimens, oral or parenteral antimicrobial therapy is selected depending on the drugs available and on the patient's history.

The choice of the antimicrobial therapy must take multiple factors into consideration (drug allergies, kidney failure, liver failure, etc.) and antimicrobials with good bone diffusion are preferred. Doses are similar to those mentioned in the various general recommendations for classic bone and joint infections $[26,58]$.

In light of ecological considerations and antimicrobial sparing, each specimen must be interpreted depending on the clinical context, gross appearance, and sample site to prevent inflationary use of broad-spectrum drugs which would lead to an individual and collective risk of bacterial resistance emergence and spread.

The duration of antimicrobial treatment for bone and joint infections has not yet been standardized $[59,60]$. Studies suggest a treatment duration of six weeks, even in the event of orthopedic device infection [61,62]. Decreasing the overall exposure to antimicrobials through short treatment durations should decrease the selective pressure on bacteria and the impact on the patient's endogenous flora $[56,63,64]$.

Data is very scarce on osteitis associated with pressure ulcers. There is no adequate rationale for the antimicrobial treatment duration. However, a short treatment duration may be sufficient, given the pathophysiology of the infection, type of bone tissue involved (spongy bone), secondary revascularization of the diseased bone due to a covering muscle 
and cutaneous flap. One study failed to show the benefit of an antimicrobial therapy administered for more than three weeks [41]. For some experts, treatment duration mainly depends on the surgical procedure but the borderline between infected and non-infected areas may be difficult to determine. Some authors did not observe any difference between an antimicrobial treatment duration of less than 5 days versus 6 weeks if the surgical procedure was satisfactory with complete resection of the infected tissues when comparing patients presenting with chronic versus acute osteitis [65]. For osteitis associated with pressure ulcers, the recommended effective treatment duration in our center is 10 days. This strategy leads to $82 \%$ of favorable outcome (i.e., no clinical recurrence at hospital discharge).

\subsection{Local antimicrobial therapy}

No convincing data is available on local antimicrobial therapy in the management of infected pressure ulcers and its benefit [66]. However, local antimicrobial therapy has interesting theoretical advantages. It prevents from systemic antimicrobial penetration and thus from drug interactions, potential systemic toxicity and the indirect emergence of bacterial resistance at the gastrointestinal flora level $[66,67]$. In that context, local antimicrobial therapy should be used alone. The reservations relate to the difficulties in combining several drugs, the empirical choice of antimicrobials, the non-homogeneity of their local diffusion, and in evaluating the elimination of products liable for bacterial resistance emergence. To our knowledge, in terms of bone involvement, no conclusive result has yet been published. A review of local antimicrobial therapy for wounds by Lipsky and Hoey indicates that the indications vary depending on the clinical definition of wound infection [67]. Clinical 
infection requires systemic antimicrobial therapy, whereas lesions with unsatisfactory course despite optimum management, particularly unpleasant smelling wounds and burns, require local devices impregnated with non-toxic antiseptics (e.g., cadexomer iodine) rather than antimicrobials [67].

\section{Prevention}

Prevention of initial pressure ulcers or ulcer recurrence in $\mathrm{SCl}$ patients is of primary importance. Investigation for risk factors must be systematically conducted and addressed if observed: optimization of nutritional status, combating immobility, maintaining vesical and sphincter equilibrium, smoking cessation, education, etc. $[9,10,68-71]$.

Patients should receive appropriate education and specialized follow-up to prevent pressure ulcer.

The numerous other aspects (social, nursing, nutritional, psychological, pain, rehabilitation) are not addressed herein.

\section{Conclusion}

The potential seriousness and the difficulty in managing infected pressure ulcers in $\mathrm{SCl}$ patients call for close cooperation between the various caregivers: orthopedic and plastic surgeons, infectious diseases specialists, microbiologists, hygienists, pharmacists, physical and rehabilitation medicine physicians and all the paramedical personnel (physiotherapists, psychologists, nurses, nursing aids, dietitians, and social assistants).

The antimicrobial treatment is only one component of the overall strategy for medical and surgical management of patients presenting with infected pressure ulcers. Antimicrobial 
chemotherapy should be shortened as much as possible ( 5 to 10 days) with the narrowest spectrum according to the microbiological identification from deep bacteriological samples. As no comparative study is available, most of the approaches in spinal cord injured patients are based on expert opinions and it is therefore necessary to enhance cooperation, to collate assessments of the various existing strategies and possibly to propose prospective and comparative studies.

\section{Disclosure of interest}

The authors report no conflict of interest.

\section{Contribution of authors}

All authors contributed to the discussion, to drafting the initial text, and proofread the final version of the article.

\section{Acknowledgement}

The authors would like to thank Elodie Choisy for her help. 


\section{$\underline{\text { References }}$}

[1] Consortium for Spinal Cord Medicine Clinical Practice Guidelines. Pressure ulcer prevention and treatment following spinal cord injury: a clinical practice guideline for health-care professionals. J Spinal Cord Med 2001;24 Suppl 1:S40--101.

[2] Fuhrer MJ, Garber SL, Rintala DH, Clearman R, Hart KA. Pressure ulcers in communityresident persons with spinal cord injury: prevalence and risk factors. Arch Phys Med Rehabil 1993;74:1172-7.

[3] Krause JS, Carter RE, Pickelsimer EE, Wilson D. A prospective study of health and risk of mortality after spinal cord injury. Arch Phys Med Rehabil 2008;89:1482-91.

[4] Regan MA, Teasell RW, Wolfe DL, Keast D, Mortenson WB, Aubut J-AL, et al. A systematic review of therapeutic interventions for pressure ulcers after spinal cord injury. Arch Phys Med Rehabil 2009;90:213-31.

[5] Dinh A, Saliba M, Saadeh D, Bouchand F, Descatha A, Roux AL, et al. Blood stream infections due to multidrug-resistant organisms among spinal cord-injured patients, epidemiology over 16 years and associated risks: a comparative study. Spinal Cord 2016;54:720-5. doi:10.1038/sc.2015.234.

[6] Waites KB, Chen Y, DeVivo MJ, Canupp KC, Moser SA. Antimicrobial resistance in gram-negative bacteria isolated from the urinary tract in community-residing persons with spinal cord injury. Arch Phys Med Rehabil 2000;81:764-9.

[7] The National Pressure Ulcer Advisory Panel. Pressure ulcers prevalence, cost and risk assessment: consensus development conference statement. Decubitus 1989;2:24-8.

[8] ANAES. Conférence de consensus : Prévention et traitement des escarres de l'adulte et du sujet âgé. Paris: ANAES; 2001.

[9] DeLisa JA, Mikulic MA. Pressure ulcers. What to do if preventive management fails. 
Postgrad Med 1985;77:209-212-220.

[10] Byrne DW, Salzberg CA. Major risk factors for pressure ulcers in the spinal cord disabled: a literature review. Spinal Cord 1996;34:255-63.

[11] Chen Y, Devivo MJ, Jackson AB. Pressure ulcer prevalence in people with spinal cord injury: age-period-duration effects. Arch Phys Med Rehabil 2005;86:1208-13.

[12] Walter JS, Sacks J, Othman R, Rankin AZ, Nemchausky B, Chintam R, et al. A database of self-reported secondary medical problems among VA spinal cord injury patients: its role in clinical care and management. J Rehabil Res Dev 2002;39:53-61.

[13] Garber SL, Rintala DH. Pressure ulcers in veterans with spinal cord injury: a retrospective study. J Rehabil Res Dev 2003;40:433-41.

[14] Taghipoor KD, Arejan RH, Rasouli MR, Saadat S, Moghadam M, Vaccaro AR, et al. Factors associated with pressure ulcers in patients with complete or sensory-only preserved spinal cord injury: is there any difference between traumatic and nontraumatic causes? J Neurosurg Spine 2009;11:438-44.

[15] Raghavan P, Raza WA, Ahmed YS, Chamberlain MA. Prevalence of pressure sores in a community sample of spinal injury patients. Clin Rehabil 2003;17:879-84.

[16] Black J, Baharestani MM, Cuddigan J, Dorner B, Edsberg L, Langemo D, et al. National Pressure Ulcer Advisory Panel's updated pressure ulcer staging system. Adv Skin Wound Care 2007;20:269-74.

[17] Agency for Health Care Policy and Research. Pressure ulcer treatment. Clin Pract Guidel Quick Ref Guide Clin 1994:1-25.

[18] Richards S, Waites K, Chen Y, Kogos S, Schmitt MM. The Epidemiology of Secondary Conditions Following Spinal Cord Injury. Top Spinal Cord Inj Rehabil 2004;10:15-29.

[19] Bowler PG, Duerden BI, Armstrong DG. Wound microbiology and associated 
approaches to wound management. Clin Microbiol Rev 2001;14:244-69.

[20] Robson MC, Mannari RJ, Smith PD, Payne WG. Maintenance of wound bacterial balance. Am J Surg 1999;178:399-402.

[21] Darouiche RO, Landon GC, Klima M, Musher DM, Markowski J. Osteomyelitis associated with pressure sores. Arch Intern Med 1994;154:753-8.

[22] Parish LC, Witkowski JA. The infected decubitus ulcer. Int J Dermatol 1989;28:643-7.

[23] Butalia S, Palda VA, Sargeant RJ, Detsky AS, Mourad O. Does this patient with diabetes have osteomyelitis of the lower extremity? JAMA 2008;299:806-13.

[24] Lavery LA, Armstrong DG, Peters EJG, Lipsky BA. Probe-to-bone test for diagnosing diabetic foot osteomyelitis: reliable or relic? Diabetes Care 2007;30:270-4.

[25] Hauptfleisch J, Meagher TM, Hughes RJ, Singh JP, Graham A, López de Heredia L. Interobserver Agreement of Magnetic Resonance Imaging Signs of Osteomyelitis in Pelvic Pressure Ulcers in Patients With Spinal Cord Injury. Arch Phys Med Rehabil 2013;94:1107-11. doi:10.1016/j.apmr.2012.11.012.

[26] Livesley NJ, Chow AW. Infected pressure ulcers in elderly individuals. Clin Infect Dis 2002;35:1390-6.

[27] Heym B, Rimareix F, Lortat-Jacob A, Nicolas-Chanoine M-H. Bacteriological investigation of infected pressure ulcers in spinal cord-injured patients and impact on antibiotic therapy. Spinal Cord 2004;42:230-4.

[28] Bernard L, Pron B, Vuagnat A, Gleizes V, Signoret F, Denormandie P, et al. The value of suction drainage fluid culture during aseptic and septic orthopedic surgery: a prospective study of 901 patients. Clin Infect Dis 2002;34:46-9.

[29] Legout L, Stern R, Assal M, Rohner P, Merle C, Hoffmeyer P, et al. Suction drainage culture as a guide to effectively treat musculoskeletal infection. Scand J Infect Dis 
2006;38:341-5.

[30] Whitney J, Phillips L, Aslam R, Barbul A, Gottrup F, Gould L, et al. Guidelines for the treatment of pressure ulcers. Wound Repair Regen 2006;14:663-79.

[31] Han H, Lewis VL, Wiedrich TA, Patel PK. The value of Jamshidi core needle bone biopsy in predicting postoperative osteomyelitis in grade IV pressure ulcer patients. Plast Reconstr Surg 2002;110:118-22.

[32] Huang AB, Schweitzer ME, Hume E, Batte WG. Osteomyelitis of the pelvis/hips in paralyzed patients: accuracy and clinical utility of MRI. J Comput Assist Tomogr 1998;22:437-43.

[33] Türk EE, Tsokos M, Delling G. Autopsy-based assessment of extent and type of osteomyelitis in advanced-grade sacral decubitus ulcers: a histopathologic study. Arch Pathol Lab Med 2003;127:1599-602.

[34] Hollisaz MT, Khedmat H, Yari F. A randomized clinical trial comparing hydrocolloid, phenytoin and simple dressings for the treatment of pressure ulcers [ISRCTN33429693]. BMC Dermatol 2004;4:18. doi:10.1186/1471-5945-4-18.

[35] Subbanna PK, Margaret Shanti FX, George J, Tharion G, Neelakantan N, Durai S, et al. Topical phenytoin solution for treating pressure ulcers: a prospective, randomized, double-blind clinical trial. Spinal Cord 2007;45:739-43. doi:10.1038/sj.sc.3102029.

[36] Kaya AZ, Turani N, Akyüz M. The effectiveness of a hydrogel dressing compared with standard management of pressure ulcers. J Wound Care 2005;14:42-4.

[37] Scevola S, Nicoletti G, Brenta F, Isernia P, Maestri M, Faga A. Allogenic platelet gel in the treatment of pressure sores: a pilot study. Int Wound J 2010;7:184-90. doi:10.1111/j.1742-481X.2010.00671.x.

[38] Norman G, Dumville JC, Moore ZEH, Tanner J, Christie J, Goto S. Antibiotics and 
antiseptics for pressure ulcers. Cochrane Database Syst Rev 2016:CD011586. doi:10.1002/14651858.CD011586.pub2.

[39] Thiessen FE, Andrades P, Blondeel PN, Hamdi M, Roche N, Stillaert F, et al. Flap surgery for pressure sores: Should the underlying muscle be transferred or not? J Plast Reconstr Aesthetic Surg 2011;64:84-90. doi:10.1016/j.bjps.2010.03.049.

[40] Sameem M, Au M, Wood T, Farrokhyar F, Mahoney J. A Systematic Review of Complication and Recurrence Rates of Musculocutaneous, Fasciocutaneous, and Perforator-Based Flaps for Treatment of Pressure Sores. Plast Reconstr Surg 2012;130:67e-77e. doi:10.1097/PRS.0b013e318254b19f.

[41] Thornhill-Joynes M, Gonzales F, Stewart CA, Kanel GC, Lee GC, Capen DA, et al. Osteomyelitis associated with pressure ulcers. Arch Phys Med Rehabil 1986;67:314-8.

[42] Goodman CM, Cohen V, Armenta A, Thornby J, Netscher DT. Evaluation of results and treatment variables for pressure ulcers in 48 veteran spinal cord-injured patients. Ann Plast Surg 1999;42:665-72.

[43] Biglari B, Büchler A, Reitzel T, Swing T, Gerner HJ, Ferbert T, et al. A retrospective study on flap complications after pressure ulcer surgery in spinal cord-injured patients. Spinal Cord 2014;52:80-3. doi:10.1038/sc.2013.130.

[44] Ljung AC, Stenius MC, Bjelak S, Lagergren JF. Surgery for pressure ulcers in spinal cordinjured patients following a structured treatment programme: a 10-year follow-up. Int Wound J 2016:Epub ahead of print. doi:10.1111/iwj.12609.

[45] Kenneweg KA, Welch MC, Welch PJ. A 9-year retrospective evaluation of 102 pressure ulcer reconstructions. J Wound Care 2015;24:S12--4, S16--21.

[46] KCI. V.A.C. Therapy Indications and Safety n.d.

[47] Smith N. The benefits of VAC therapy in the management of pressure ulcers. Br J Nurs 
2004;13:1359-65. doi:10.12968/bjon.2004.13.22.17277.

[48] Mouës CM, Heule F, Hovius SER. A review of topical negative pressure therapy in wound healing: sufficient evidence? Am J Surg 2011;201:544-56. doi:10.1016/j.amjsurg.2010.04.029.

[49] Huang C, Leavitt T, Bayer LR, Orgill DP. Effect of negative pressure wound therapy on wound healing. Curr Probl Surg 2014;51:301-31. doi:10.1067/j.cpsurg.2014.04.001.

[50] Ngo QD, Vickery K, Deva AK. The effect of topical negative pressure on wound biofilms using an in vitro wound model. Wound Repair Regen 2012;20:83-90. doi:10.1111/j.1524-475X.2011.00747.x.

[51] Batra RK, Aseeja V. VAC Therapy in Large Infected Sacral Pressure Ulcer Grade IV-Can Be an Alternative to Flap Reconstruction? Indian J Surg 2014;76:162-4. doi:10.1007/s12262-012-0770-7.

[52] Gabriel A, Shores J, Bernstein B, de Leon J, Kamepalli R, Wolvos T, et al. A Clinical Review of Infected Wound Treatment with Vacuum Assisted Closure (V.A.C.) Therapy: Experience and Case Series. Int Wound J 2009;6 Suppl 2:1-25. doi:10.1111/j.1742481X.2009.00628.x.

[53] Royal College of Nursing (UK). The Management of Pressure Ulcers in Primary and Secondary Care: A Clinical Practice Guideline. London: Royal College of Nursing (UK); 2005.

[54] Dow G, Browne A, Sibbald RG. Infection in chronic wounds: controversies in diagnosis and treatment. Ostomy Wound Manage 1999;45:23-27-42.

[55] SPILF. Érysipèle et fasciite nécrosante: prise en charge. Faculté de Tours. Med Mal Infect 2000;30:245-6.

[56] Wintenberger C, Guery B, Bonnet E, Castan B, Cohen R, Diamantis S, et al. Proposal for 
shorter antibiotic therapies. Med Mal Infect 2017;47:92-141. doi:10.1016/j.medmal.2017.01.007.

[57] Wits $\varnothing$ E, Persen L, Løseth K, Bergh K. Adsorption and release of antibiotics from morselized cancellous bone. In vitro studies of 8 antibiotics. Acta Orthop Scand 1999;70:298-304.

[58] Galpérine T, Bernard L. Antibiotic therapy of osteoarticular infections in the adult. Rev Prat 2007;57:995-1002.

[59] SPILF. Recommandations de Pratique Clinique: infections ostéo-articulaires sur matériel (prothése, implant, ostéosynthèse). Med Mal Infect 2009;39:745-74.

[60] Choutet P, Desplaces N, Evrard J, Quinet B, Peyramond D, Lopitaux R, et al. [Traitement des infections ostéo-articulaires bactériennes en dehors des infections à mycobactéries].[Article in french]. Med Mal Infect 1991;21:546-50. doi:10.1016/S0399-077X(05)80112-X.

[61] Bernard L, Hoffmeyer P, Assal M, Vaudaux P, Schrenzel J, Lew D. Trends in the treatment of orthopaedic prosthetic infections. J Antimicrob Chemother 2004;53:127-9.

[62] Hoad-Reddick DA, Evans CR, Norman P, Stockley I. Is there a role for extended antibiotic therapy in a two-stage revision of the infected knee arthroplasty? J Bone Jt Surg 2005;87:171-4.

[63] File TM. Clinical efficacy of newer agents in short-duration therapy for communityacquired pneumonia. Clin Infect Dis 2004;39 Suppl 3:S159--S164.

[64] Goossens H, Ferech M, Stichele V, Elseviers M, on behalf of ESAC Project Group. Outpatient antibiotic use in Europe and association with resistance: a cross-national database study. Lancet 2005;365:579-87. 
[65] Marriott R, Rubayi S. Successful truncated osteomyelitis treatment for chronic osteomyelitis secondary to pressure ulcers in spinal cord injury patients. Ann Plast Surg 2008;61:425-9.

[66] AFSSAPS. [Prescription des antibiotiques par voie locale dans les infections cutanées primitives et secondaires][Article in French] 2004.

[67] Lipsky BA, Hoey C. Topical antimicrobial therapy for treating chronic wounds. Clin Infect Dis 2009;49:1541-9.

[68] Krause JS, Vines CL, Farley TL, Sniezek J, Coker J. An exploratory study of pressure ulcers after spinal cord injury: Relationship to protective behaviors and risk factors. Arch Phys Med Rehabil 2001;82:107-13.

[69] Lane CA, Selleck C, Chen Y, Tang Y. The Impact of Smoking and Smoking Cessation on Wound Healing in Spinal Cord-Injured Patients With Pressure Injuries. J Wound, Ostomy Cont Nurs 2016;43:483-7. doi:10.1097/WON.0000000000000260.

[70] Ho CH, Powell HL, Collins JF, Bauman WA, Spungen AM. Poor Nutrition Is a Relative Contraindication to Negative Pressure Wound Therapy for Pressure Ulcers. Adv Skin Wound Care 2010;23:508-16. doi:10.1097/01.ASW.0000390493.43835.ec.

[71] Schubart JR, Hilgart M, Lyder C. Pressure Ulcer Prevention and Management in Spinal Cord-Injured Adults. Adv Skin Wound Care 2008;21:322-9. doi:10.1097/01.ASW.0000323521.93058.47. 
Table I. Pressure ulcer classification as per the National Pressure Ulcer Advisory Panel and the French National Authority for Health (French acronym HAS) [8,9]

Tableau I. Classification des escarres selon le National Pressure Ulcer Advisory Panel et l'HAS $[8,9]$

The first stage is an observable impairment of intact skin related to pressure and presenting as a change in one or several of the following characteristics compared with the adjacent or contralateral body area: temperature of the skin (warmer or cooler),

Stage I tissue consistency (firm or soft), and/or sensitivity (pain, itching).

In subjects with light skin, the pressure ulcer presents as a localized persistent redness while in subjects with pigmented skin the pressure ulcer may have a persistent red, blue, or violet color.

Partial loss of the skin thickness. The loss affects the epidermis, the dermis, or both.

Stage II The pressure ulcer is superficial and clinically presents as an abrasion, blister, or shallow ulcer.

Full loss of tissue thickness with impairment or necrosis of the subcutaneous tissue. This

Stage III may extend to the fascia but not beyond. Clinically, the pressure ulcer presents as a deep ulcer with or without invasion of neighboring tissues.

Full loss of the skin thickness with marked destruction of the tissue or involvement of

Stage IV the muscles, bone or supporting structures (e.g., tendons and joints).

Invasion and fistula may be associated with stage IV pressure ulcer. 
Table II. Risk factors for pressure ulcers [9]

Tableau II. Facteurs de risque des escarres [9]

Extrinsic risk factors $\quad$ Pressure, friction, shearing, and maceration of the skin

Immobility; nutritional status and malnutrition; urinary and fecal incontinence; skin condition; reduction in blood flow rate;

Intrinsic risk factors neuropathy responsible for a loss of sensitivity and inability to change position; psychological state and loss of motivation to take part in care; age

Risk factors under debate

Dehydration; some acute diseases; serious chronic diseases; terminal phase of serious diseases 